\title{
4
}

\section{State Power, Spatial Inequality, and Geographical Expertise: Notes on Method}

\author{
Merje Kuus
}

\section{Introduction: Policy Expertise in Transnational Processes}

This chapter is about policy, state power, and research method. My practical questions are about the everyday creation of policy expertise. I ask: how is expert authority made in transnational policy settings? More specifically, how is the everyday creation of policy expertise changing today, as ever more state and non-state actors participate in policy-making at both national and international levels? Where are the centres and margins of expertise in a political space like the European Union and how do the fortunes of specific places rise and fall in these processes? What is the role of states and national institutions in this process and how are these institutions transformed in the process of transnational policy-making?

M. Kuus ( $\square)$

University of British Columbia, Vancouver, BC, Canada 
Intersecting with these practical questions about state power are methodological puzzles and dilemmas about how we ought to study transnational policy expertise and the role of states in it. What can we take as evidence of transnational dynamics in the context in which most information is produced by nationally affiliated experts and commentators? The chapter is indeed as much about research method as it is about policy, expertise, or state power in Europe.

The chapter will proceed in three steps. I will first make an argument about the transnationalisation of policy knowledge in Europe: the ways in which policy expertise, including state-governing expertise, is produced in ambiguous and ephemeral transnational networks. I will then highlight some of the ways in which that process of transnationalisation is fundamentally uneven and may indeed accentuate rather than reduce existing inequalities in the field of policy expertise in Europe. I will finally foreground some of the methodological challenges encountered in the study of transnational policy processes. My empirical examples come from the fields of diplomacy and diplomatic training, but my effort is to illuminate the dynamics of knowledge production in policymaking institutions more broadly. ${ }^{1}$

Diplomacy and other such knowledge-intensive fields are important to examine because experts in these fields craft the knowledge claims on which basis policies are made in the first place. Experts do not simply tell us how things work or ought to work. Experts also tell us what exists, what is significant, and what is possible. Policy-making is in part an administrative practice. It is also an intellectual and imaginative social practice.

My empirical analysis is based on ten years of work. It draws in part from about 160 one-to-one loosely structured interviews with foreign policy professionals, mostly diplomats. The interviews were conducted with over ninety such professionals between 2007 and 2017, in small sets of 10-15 interviews per year. They were carried out mostly but not exclusively in Brussels (cf. Kuus 2014, 2017a). My goal was not to find out what diplomats think about particular policy issues. Rather, I tried to elucidate the rules for the production of rules in diplomatic institutions. My enquiry is ultimately about knowledge and state power. 
Most of the direct quotes that I bring from that material come from a smaller and more recent sub-set of the material: about fifty interviews that focus specifically on the transnationalisation of regulatory power and the diplomatic profession today. These fifty interviews were conducted in Brussels and eight other nodes of diplomatic knowledge in the last three years. Most of them probe the transnationalisation of state-governing expertise: the transnational networks of ideas and influence through which state power is produced and transformed today.

\section{Transnationalisation of States}

In the facet that is easily visible in daily practice and academic research, diplomacy is about the inter-national negotiation of national interests. So is EU policy-making. The most important decisions in the EU are taken intergovernmentally and inter-nationally. Even in the supposedly supranational settings of the European Commission, national perspectives are clearly discernible and carefully guarded. "The most important skill in Brussels is nationality", a long-time observer remarks caustically about EU policy-making. Many if not most issues and debates in Brussels are habitually plotted onto a national matrix in which power is viewed in terms of the competition and collaboration among pre-given entities called nation-states (Kuus 2015).

Yet, the daily grind of diplomatic work is becoming increasingly trans-national rather than inter-national: it involves substantial transnational circulation and mutation of ideas and practices. When one looks at how diplomats actually do their work, and when one really tries to notice what one usually does not notice, the picture is not so inter-national. When one tries to see not only what diplomats do today but also what they are willy-nilly being trained and socialised to do in twenty years, a more transnational scene emerges.

As an example of the ambiguous feel of the shifts at hand, consider this culinary metaphor from a national diplomat in Europe. The greatest difficulty in European Union decision-making, he observes, is coordinating the underlying approaches to issues: the ways of looking at 
problems, the methods of addressing them administratively. You can develop procedures for communication, but the often unconscious lenses, deeply rooted in national cultures, are hard to alter. The difficulty is often underestimated, the interviewee observes. "There is a nice European sauce that someone has poured over the differences [he makes a gesture of pouring something over a dish carelessly and in copious quantities]", but this often only coats and masks rather than harmonises the differences.

At first glance, this diplomat stresses the inter-national character of diplomacy. The sauce is cast as a useless obstruction on an inter-state scene. But it is noted. There is something in addition to the inter-national shaping that dish. If we overemphasise the sauce, we lose something. But if we ignore the sauce, we also miss something. There is a tendency to focus on the so-called real stuff-states- underneath the sauce. The tendency is there in part because the causal powers of the sauce cannot be neatly identified. It is easy to identify a state as an actor. In diplomacy and in EU policy-making, these are literally states who speak in negotiations settings: France says this or Germany says that. Identifying an agent in a diffuse transnational web of activity is far more difficult.

In diplomacy, foreign ministries still do most of the professional training. At first glance, the various initiatives, which I will not review here (see Kuus 2017a), seem to illustrate mostly the inter-national connections of state institutions. In addition to the business as usual, diplomatic training also extends beyond state structures and operates through transnational competition for resources both material and symbolic. Most visibly, many courses operate at the margins or outside of formal ministerial structures, via universities, research institutes, foundations, or consulting companies.

State power also operates through long-term structural tendencies rather than specific formal policies. For example, a number of EU member states, more so the richer than the poorer ones, offer scholarships to their nationals to study at the College of Europe, a specialist post-graduate institution that has long served as a training ground of EU civil servants. The states do this in the hope that these graduates subsequently succeed in EU institutions and put their national perspectives in play in EU structures. These initiatives do not amount to 
diplomatic training in formal terms, but they illustrate the recognition among nation-states that effective long-term influence requires actions much beyond the national capital (Kuus 2018).

When one tries to understand what places matter in the European field of diplomatic expertise, one needs to consider not only states or institutions as such. One also has to consider the various institutions' and training initiatives' alumni networks in Brussels and around the world. In such networks, state power is modulated through intangible symbolic resources, such as reputation. For example, how do we assess the importance of an alumni network around the London School of Economics and Political Science, the Johns Hopkins University Centre in Bologna, the European University Institute in Florence, or Tufts University in Cambridge, Massachusetts? If we look at diplomatic training as a broader social field of connections and struggles, we begin to discern patterns that are not neatly intergovernmental or inter-national, but operate along transnational axes of differentiation.

Many of the diplomats I interview in Europe note the distinctiveness of EU-level diplomacy: both the negotiations among the member states and the external diplomacy of the EU as a whole. "The Brussels skill... [a diplomat says, while appearing to be sifting sand through his fingers] ... you cannot apply what you learned in your ministry". Influence in the EU, The Economist (2013) magazine remarks along similar lines, is like the Brussels drizzle: ubiquitous but hard to pinpoint. It is observable not in its application at any one point in time but in its cumulative effects over time. It may be fashionable in some capitals to glorify the 'big boys' bilateral diplomacy over what The Economist calls the "delicate dance" (The Economist 2014) in Brussels, but the diplomats sent to do the dance are often the most skilled these same capitals can muster. When Britain's Permanent Representative resigned unexpectedly in early 2017, many noted that losing someone so well-versed in the "silken culture” of Brussels ought to worry London (D’Ancona 2017).

Even in large foreign services, skilled diplomats recognise that Brussels ups the game for them. In a national diplomacy, a diplomat observes, you advance the national interest, which, for practical purposes, is expressed by the government in office. In EU diplomacy, you further the European interest. But what is that? It has to be distilled, 
felt: it is constantly challenged and revised. Several interviewees, in different diplomatic services, instinctively reach for tactile gestures to characterise the process. It might be a gesture of feeling a fabric between their fingers to test its quality. Or the gesture of sifting sand through their fingers to feel its grain. Or feeling something amorphous and hard to grasp. As my work on diplomatic training has progressed, remarks about what I call the cloth gesture increasingly appear in my notes as I learn to notice such gestures.

The gestures convey something intangible and qualitative: something that can be discerned, but not measured. Once I dare to consider the references to silk and drizzle as evidence of slow and diffuse shifts in atmosphere and relations, different long-term futures come into relief. Once I ask what kinds of spaces diplomats are being prepared for, not in the next year but in the next twenty years, I realise that inter-national spaces these are not-at least not in the minds of the more light-footed among the dancers.

As an example, consider the following vignette. When Brussels began to ponder the impending retirement of Pierre Sellal, France's Permanent Representative, and the acknowledged Sun King of the Brussels diplomatic scene, even the admirers of his "light-footed charm" noted that Sellal may be the last of his kind. His "parlour games" of big player alliances, Salmon Mousseline, and bottles of Grand Cru worked well so far, but the new representative may need to work with a broader range of actors. In the "somewhat regretful" characterisation of the parlour game from a diplomat from an Eastern European who said: "Pierre never had to approach me for support. He had always his majority arranged and ... elegantly presented at the meeting" (De la Baume and Vinocur 2016). Some of those in the parlours take note of that regretful tinge and wonder whether France can afford to be so confident about its influence. "He's sometimes too French", a French diplomat says of Sellal: "He is the Frenchman who knows the Brussels machine best. The question now is, the diplomat continues, whether this version of Brussels corresponds to the reality of today" (ibid.). If the French, whose diplomacy is highly regarded in Brussels, may need to reconsider their approach, is the big power game really an option for any member state? 
Traditional categorisations of interest and identity have modest utility in these circumstances. The neat terminology of levels and stages of decision-making - national, European, Brussels, and so on-is of limited value as the actual daily horse-trading does not follow the binaries of national vs. European or intergovernmental vs. supranational. The question is not who has the upper hand in the relations between Brussels and the member states. The question is how to analyse regulatory power in Europe without that binary of Brussels and the member states and without the national matrix that imagines power in state-based terms and thereby unimagines transnational connections (Kuus 2017b).

\section{Uneven Europe}

Yet, this is not some kind of mythical harmonised space of European expertise. It is a space of knowledge articulated through existing power relations. I will thus briefly delve into some of the uneven and unequal patterns in that space. One of such intangible resources concerns societal wealth-both government spending and the broader societal wealth discernible through the sophistication of the media, education, and social scene more broadly.

Diplomatic protocol codifies the nominal parity of states and encourages the polite pretence of it. Specialist literature customarily presents the profession in terms of national perspectives. It implies that one can jump from power centres to power margins with examples; that the training programmes, university research, or journalistic reporting generated in different countries are usually on par. The little secret is that diplomatic expertise is expensive. Its production requires long-term strategic spending much beyond the foreign ministry. Put bluntly, symbolic capital costs money.

This comes to the fore in Brussels. In that node of global power, work is more "sociological" than traditional bilateral diplomatic practice, an interviewee explains. It requires a certain intangible feel for the game. That feel does not come cheaply. The richer countries can start with a better prepared pool of applicants because they have better universities and a more sophisticated media landscape. These more affluent systems 
can weigh and debate the importance of thematic, regional, or other forms of expertise. They can appoint advisors to do some of this work. They can rotate diplomats widely and benefit from the diverse networks forged in the process. The less well-to-do systems focus on the skills that they can train quickly and cheaply in-house.

For some of the poorer EU member states, seconding junior diplomats to the EU diplomatic service as desk officers at geographical units is their best chance to give these professionals some exposure to distant places. Without continuous exposure to regional expertise in the home capital as well, the long-term effect is uncertain. The impact of such long-term exposure is difficult to measure. Qualitatively, it plays. One can see, a council official speaks of the negotiations there, that big rich countries' diplomats' knowledge of, say, Africa, is qualitatively better from what those from small Central European countries can muster. The small countries are understandably sensitive to their immediate neighbourhood. In EU settings though, the game is often bigger and Eurocentric knowledge is insufficient.

In theory, the smaller and poorer countries can use digital technologies to access information and networks without training diplomats to be present physically. In practice, there is, to quote two different interviewees, a "huge", even "growing" gap between possibility and reality. In addition to the visible power, visible from things like diplomats being around the table, there is, what yet another interviewee calls the invisible power of personal networks. That invisible power cannot be acquired via an e-mail list: it requires long-term inter-personal relationships of professional trust. In Brussels, what plays is not only the instructions and negotiation skills in Brussels, but, more broadly, the pre-Brussels training and socialisation (Kuus 2018).

The differences in wealth should not be overplayed and the unevenness cannot be captured by GDP figures. Generalisations must be done tentatively. "It seems to me", I solicit feedback from a senior diplomat, "that if someone comes from a relatively rich diplomatic service, where there is some space for a certain-relaxed-exploration of complex social issues, that person is better prepared for Brussels than someone who comes from a shoestring ministry, equipped with unrealistic instructions and little else". "The important word there is 'relaxed', 
not 'rich", the person responds. Stable ministries with long traditions, including the traditions of mentoring, fare better, but it is the tradition rather than the budget that plays. There are examples, the interviewee continues, of relatively poor countries with strong diplomatic services owing to that benefit of tradition. Nobody cites a rich country without a strong tradition. Wealth brings you the tradition in any event (see also Kuus 2018).

The picture that is beginning to emerge is a networked transnational market for diplomatic expertise. Nation-states, aided by nationally based foundations and universities, buy and sell their expertise in Europe and beyond: the poorer ones tend to buy and the richer ones tend to sell. The boundaries between state and non-state actors are growing more ambiguous and permeable. Formal institutional structures matter alongside intangible symbolic resources like connections and reputation. Transnationalisation does not undo national power or the pecking orders of states. It complicates these orders and it problematises the whole idea of a nationally based pecking order.

\section{Method: Studying Everyday Practice}

The preceding material raises methodological questions about what we take as evidence, and what conclusions we draw on the basis of that evidence-or, more broadly, how we know what we know. The rest of the chapter focuses on that question. It thereby probes some of the key methodological difficulties with analysing opaque transnational policy processes.

Power in Brussels is fundamentally about contextualisation: about the capacity to advance long-term national interests in the context of that specific place. Much of that knowledge is contextual, place-based, and atmospheric. It is in the air like a drizzle, like water vapour, like fragrance. And it is embodied, tightly linked to the personal knowledge, skill, reputation, and networks of individual diplomats. Looking for clear or hard evidence cannot uncover it. Methodologically, bringing out the subtle transnationalisation of European diplomacy (and policy 
expertise) requires that we work with the "regretful tinge" and the barely discernible criticism of parlour games from the French themselves. But how to articulate such atmospheric issues in a rigorous scholarly manner? To what degree are references to silk and dance and mousseline, or the cloth gestures, serious evidence rather than anecdotes, interpretations, or otherwise insubstantial speculation?

Analysing a transnational field requires attention to patterns that are at once diffuse and specific. This is difficult given that data sources are national and the interviewees tell stories that are national both at the level of overt talking points and at the level of subterranean angles and habits. Telling a different story requires a sustained effort to start somewhere else than an intergovernmental network of national foreign ministries. In order to trace the transformation of state power in diplomatic practice, we need to move beyond common-sense labels like nation-states or Europe and closely trace the blurring of these categories in empirical terms. This requires that we move beyond institutional dynamics and take the mundane and informal building blocks of daily life as our object of analysis.

Methodologically, this requires that we take the ephemeral, metaphorical, and opaque remarks about the transformations of diplomatic work seriously. References to "the Brussels skill", "the delicate dance", "the drizzle" of influence, or the "silken" character of the EU scene indicate not a different hierarchy of states but a certain deliquescent and diaphanous transformation of the diplomatic field. The effect of "the Brussels drizzle" can be discerned not in any one moment but in the social field over time. Methodologically, the task is to give an account of the contingency of diplomatic practice without squashing it into a pre-made typology, model, or storyline. The task is equally to notice practices that exceed and evade formal institutional structures and governmental positions. In the study of transnational spatial practice, empirical data are necessarily more fragmented and amorphous than official papers would lead one to believe. Such a study requires not only a matter of different data, such as interviews and direct in situ observations. It also requires that we notice different things in the data and not purify the messiness of daily life in advance of the analysis (Barry 2013, 27). 
We must keep in mind that 'careful' and 'comprehensive' are not the same thing: in the study of diffuse phenomena, the two goals may indeed contradict each other (Kelty 2008, 20). Focusing on place as a central component of the context helps one to discern the silken delicacy of situated and place-specific relationships in ways that the content analysis of policy documents disallows. We cannot overcome the constrictions of structuralist models (Adler-Nissen 2016,2) by the methods that produced these models.

It is one thing to note such details as anecdotes; it is another to craft a rigorous scholarly study from them. Transnational connections are emergent and evaporative: nationally produced documents do not tout them and national civil servants do not highlight them. Discerning these patterns requires concerted analytical effort.

To study practice is to explore:

the ways of frequenting or dwelling in place $[\ldots]$ and on the many ways of establishing a kind of reliability within the situation imposed on an individual [...] Like the skill of a driver in Rome or Naples, there is a skill that has its connoisseurs and its aesthetics exercised in any labyrinth of powers, a skill ceaselessly recreating opacities and ambiguities-spaces of darkness and trickery-in the universe of technocratic transparency. (De Certeau 1984, 18, xxii)

Efforts to codify all procedures, by giving maximum location and identification data on the interviews, for example, can obscure rather than reveal these opacities and ambiguities. Michel de Certeau (1984, 21), a French cultural theorist, writes:

Of the practices themselves, science will retain only moveable elements (tools and products to be put in display cases) or descriptive schemas (quantifiable behaviours, stereotypes of the staging of social intercourse, ritual structures), leaving aside the aspects of society that cannot be so uprooted and transferred to another space: ways of using things or words according to circumstances. [...] Indeed, like Schreber's God, who 'communicates only with cadavers' our knowledge seems to consider and tolerate in a social body only inert objects. 
The kind of study de Certeau advocates requires us to see different patterns in the ephemeral intersubjective situation of iteration. The task is, in part, to wilfully focus on what does not seem to exist. This is tricky. Wilful interpretation can easily become wishful thinking. Labelling something transnational rather than intergovernmental in origin does not make it that.

The references to dance and silk and mousseline are all direct quotes from journalistic reporting. I just make more of these fleeting references than I usually dare to do. I take them seriously as evidence of a series of transformations in state power and state-governing expertise in Europe. I accentuate the individual, the contextual, the embodied, the experiential, and the fleeting in both primary and secondary research. I make much of the small comments and halfthoughts that destabilise the business as usual but tend to be brushed aside in traditional state-centred accounts. A big part of such data is publicly available, in gossip, newspaper commentary, and daily life. I do not necessarily need to do a traditional ethnography in Brussels. There are plenty of observant people in Brussels and they write plenty. What I need, and often find difficult, is a different kind of awareness and risk-taking ahead of the collection of data. We must be keenly aware of the distinction between categories of practice and categories of analysis. Ask a practitioner of diplomacy about her profession and she will tell you a story of national interests. But this does not mean that your analysis of diplomatic practice has to be statebased as well.

Analysing a transnational field requires attention to patterns that are at once diffuse and specific. This is difficult: data sources are national and the interviewees tell stories that are national both at the level of overt talking points and at the level of subterranean angles and habits. Telling a different story requires a sustained effort to start somewhere else than an intergovernmental network of national foreign ministries. In order to trace the transformation of state power in diplomatic practice, we need to move beyond common-sense labels like nation-states or Europe and closely trace the blurring of these categories in empirical terms. This requires that we move beyond institutional dynamics 
and take the mundane and informal building blocks of daily life as our object of analysis.

This underscores the importance of methodological and conceptual pluralism in the study of international practice and social power. Diplomacy is a fine empirical lens through which to practise such pluralism. To effectively represent the interest of their states, diplomats must be open to encounters with difference. This, in turn, requires that they wear their pre-existing assumptions about places lightly. The single most frequent qualifier in my interview material concerns the contingency of interests, alliances, priorities, policies, outcomes. The more experienced the diplomat, the more likely they are to cite contingency and context-specificity. True, such performative production of contingency is partly a habit of negotiation: to cite contingency is to guard your cards. The category is not entirely devoid of substance, though; alert openness to context and contingency is central to diplomatic skill. "The first and best advice I can give a young man entering this career", the Earl of Malmesbury wrote in 1813, "is to listen, not to talk —at least, not more than is necessary to induce others to talk" (Roberts 2009, 619, emphasis in original).

\section{Conclusion: For Open-Ended Questions}

The chapter made three points. The first concerned the transnationalisation of policy expertise, the second concerned the uneven character of the process, and the third concerned the methodological difficulties of trying to create an analytically rigorous and empirically nuanced account of these processes. My overall effort is to nudge us toward a more openended analytical and methodological framework, less beholden to the usual formulations around the levels and scales of analysis.

A central difficulty with comprehending spatial planning in today's Europe stems from the methodological nationalism of our analytical toolbox. The power of European institutions and the patterns generated by EU-level funding, knowledge, and influence tend to be fitted into an international framework. As a result, EU power is treated as a 
veneer on an otherwise national picture. This obscures the parallel process: the ways in which national labels serve as a veneer on EU regulations. The analytical task is not to figure out where the nation-state ends and the EU begins, but to acknowledge that Europe and its member states are not distinct politically or analytically. European Union regulations present themselves to the observer in national form, but they are transnational rather than national in content and origin (Kuus 2017b). To highlight this is not to imply some mythical happy family of united Europe. The continent has been a deeply unequal space economically and politically since the inception of the modern idea of Europe in the eighteenth century. An explicitly transnational rather than national starting point gives us a more flexible framework in which to investigate the ever-shifting patterns of economic, political, and symbolic peripherality. The methodological argument reminds us about the inherent ambiguity and indeterminacy of these processes. The methodological dilemmas about what exists, how we know this, and how we come to know this, cannot be resolved: they can only be pondered.

Faced with such interminable ambiguity, I end with a quote from one of my interlocutors in Brussels. Whatever else diplomats might do, that experienced practitioner observes, they "must be open, to see new patterns". An intellectual and experiential openness is good advice for those interested in unpacking the emergent transnational patterns of expert knowledge and state power.

Acknowledgements Research for this chapter was supported by the Social Sciences and Humanities Research Council of Canada. I thank Thilo Lang and the audience in Leipzig for engaging with my argument.

\section{Note}

1. I do not review the voluminous literature on state power, transnational fields, EU policy-making, diplomacy, or ethnographic methods. The citations are available in the studies referenced herein. 


\section{References}

Adler-Nissen, Rebecca. 2016. "Towards a Practice Turn in EU Studies: The Everyday of European Integration.” JCMS: Journal of Common Market Studies 54 (1): 87-103. https://doi.org/10.1111/jcms.12329.

Barry, Andrew. 2013. Material Politics: Disputes Along the Pipeline. Chichester: Wiley-Blackwell.

D’Ancona, Matthew. 2017. "Sir Ivan Rogers' Sudden Departure Is a Hit to Theresa May's Brexit Plans." The Guardian, January 3. https://www.theguardian.com/commentisfree/2017/jan/03/brexit-ivan-rogers.

De Certeau, Michel. 1984. The Practice of Everyday Life. Berkeley: University of California Press.

De la Baume, Maia, and Nicholas Vinocur. 2016. "The Last Sun King of French Diplomacy." Politico Europe, November 25. https://www.politico.eu/ article/the-last-sun-king-french-diplomacy-pierre-sellal/.

Kelty, Christopher. 2008. Two Bits: The Cultural Significance of Free Software. Durham: Duke University Press.

Kuus, Merje. 2014. Geopolitics and Expertise: Knowledge and Authority in European Diplomacy. Chichester: Wiley-Blackwell.

Kuus, Merje. 2015. "Transnational Diplomacy in Europe: What Is Transcended and How?" In Diplomatic Cultures and International Politics: Translations, Spaces and Alternatives, edited by Jason Dittmer and Fiona McConnell, 41-58. London: Routledge.

Kuus, Merje. 2017a. "Transnational Institutional Fields: Positionality and Generalization in the Study of Diplomacy." Political Geography (early view). https://doi.org/10.1016/j.polgeo.2017.02.008.

Kuus, Merje. 2017b. "Locating Europe's Power, or the Difference Between Passports and Passporting." Discussion Forum (with Fiona McConnell, Alex Jeffrey, Adrian Smith, Nick Vaughan-Williams, and Heaven Crawley) "Interventions on Europe's Political Futures." Political Geography 60: 261-71. https://doi.org/10.1016/j.polgeo.2017.02.003.

Kuus, Merje. 2018. "Political Economies of Transnational Fields: Harmonization and Differentiation in European Diplomacy." Territory, Politics, Governance 6 (2): 222-39. https://doi.org/10.1080/21622671.201 6.1266960.

Roberts, Ivor. 2009. Satow's Diplomatic Practice. 6th ed. New York: Oxford University Press. 
The Economist. 2013. "Anatomy of a Failure." The Economist, March 9. https:// www.economist.com/news/europe/21573138-britains-defeat-over-bankers-bonuses-sign-declining-influence-anatomy-failure.

The Economist. 2014. "Dance of the Powers." The Economist, September 6. https://www.economist.com/news/europe/21615618-debate-over-eus-topjobs-has-little-do-europes-many-challenges-dance-powers.

Open Access This chapter is licensed under the terms of the Creative Commons Attribution 4.0 International License (http://creativecommons. org/licenses/by/4.0/), which permits use, sharing, adaptation, distribution and reproduction in any medium or format, as long as you give appropriate credit to the original author(s) and the source, provide a link to the Creative Commons license and indicate if changes were made.

The images or other third party material in this chapter are included in the chapter's Creative Commons license, unless indicated otherwise in a credit line to the material. If material is not included in the chapter's Creative Commons license and your intended use is not permitted by statutory regulation or exceeds the permitted use, you will need to obtain permission directly from the copyright holder.

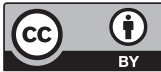

